\title{
Impact Assessment of Driver Distraction by Cellphone on Start- up Lost-time and Average Saturation Headway at Signalized Intersections Based on Vehicle Position in the Queue
}

\author{
Nawaf Alshabibi ${ }^{1 *}$ \\ ${ }^{1}$ Urban and Regional Planning Department, College of Architecture and Planning, Imam Abdulrahman Bin Faisal University, \\ P. O. B. 1982, Dammam 31433, Saudi Arabia \\ * Corresponding author, e-mail: nalshabibi@iau.edu.sa
}

Received: 04 July 2020, Accepted: 07 August 2020, Published online: 08 December 2021

\begin{abstract}
Cellphone usage has a significant impact on signalized intersections' capacity and level of service. This study investigated the impact of cellphone usage on signalized intersection capacity and level of service in Dammam Metropolitan Area, Saudi Arabia. The data included 183 useful cycles and 2407 start-up lost time and average saturation headway values at cycles with cellphone usage and cycles without cellphone usage at 24 signalized intersections. The main hypothesis of the study is that cellphone usage increases the start-up lost time at signalized intersection capacity. The secondary hypothesis is that cellphone usage increases the average saturation headway at signalized intersections. Normal distribution and z-test were conducted to assess whether there is a significant increase in average saturation headway and start-up lost time. The study found a significant increase in start-up lost time of about 0.7 seconds but found no significant increase in average saturation headway due to cellphone usage. Also, start-up lost time increases as vehicles of cellphone users get closer to the stop line of the signalized intersections. Thus, cellphone usage decreases the progression of 13 vehicles per hour due to a reduction in effective green time, increases total delay, and deteriorates the level of service. The study can assist transportation and traffic officials to optimize signal operation to mitigate the impact of cellphone usage and improve urban transportation.
\end{abstract}

Keywords

driver distraction, cellphone, average saturation headway, start-up lost time, intersection capacity, level of service

\section{Introduction}

Globally, cellular phones have been considered as a major source of driver distractions since their early days. These distractions include increased response time to roadway hazards (Alm and Nilsson, 1995), speeding on familiar uninterrupted flow facilities like freeways and arterials ( $\mathrm{Wu}$ and $\mathrm{Xu}, 2018$ ), most risky secondary activity while driving (Prat et al., 2017), reduced reaction time to signal change (Hurwitz et al., 2013), and reduced driving performance (Thapa et al., 2015). With the presence of smartphones, the problem has even become worse for two reasons. Firstly, the use of smartphones goes beyond making phone calls or simple text messages to communicating through social media, live video broadcast, internet browsing, road navigation, and audiovisual entertainment. Secondly, most of the current smartphones rely on touch screen technology as the primary input medium, which requires users to gaze at the phone screen to confirm their input choices (Oviedo-Trespalacios et al., 2019). Thus, the magnitude of distraction due to the smartphone usage is increasing drastically and is leading to more roadway accidents in many countries around the globe (NHTSA, 2010; Yuanyuan et al., 2017). For example, it is noteworthy to mention that a vehicle traveling at 120 kilometers per hour sways for 2 meters during a one second period of the driver's visual distraction (Smith et al., 2010). In France, a study found that 9\% of all drivers are using their cellphones while driving (Yuanyuan et al., 2017), and 70\% of all young drivers are using their cellphones for texting and calling while driving (Strayer et al., 2006). About 10\% of all injury crashes in France are caused by drivers using their cellphone while driving (Yuanyuan et al., 2017), and 10\% of all fatal crashes in the United States have involved cellphone distraction while driving (NHTSA, 2010). 
Within the past years, the problem of distracted driving has been investigated from different aspects of transportation and traffic engineering, globally. In the available literature, studies investigated the impact of using a cellphone while driving on driving performance (Alm and Nilsson, 1995; Liu et al., 2012; Strayer and Drews, 2003; Strayer et al., 2006; Saifuzzaman et al., 2015; Zhang and Prevedouros, 2011), traffic safety (Khandakar et al., 2019; Xiao and Shi, 2016), and traffic operation and capacity (Brumfield and Pulugurtha, 2011; Hurwitz et al., 2013; Huth et al., 2015). Some studies have shown that the significant increase in response time to roadway hazards due to phone usage and texting have a significant impact on traffic safety (Khandakar et al., 2019; Xiao and Shi, 2016). However, the impacts of distracted driving are not limited to road and passenger safety but they also apply to transportation infrastructure capacity. The literature indicates that studies on the impact of phone usage on the capacity of traffic facilities are rare (Brumfield and Pulugurtha, 2011; Hurwitz et al., 2013; Huth et al., 2015). In congested intersections, there may not occur a hazardous accident due to phone usage, unlike delay, loss in capacity, and deterioration on level of service (LOS), which is expected to be significant.

A few studies investigated the impact of using cellphones while driving on traffic capacity conducted in Oregon, Kansas, Utah, North Carolina, and in Leon, France, where signalized intersections are operating two approaches during effective green and the cycle length is 180 seconds at maximum (Brumfield and Pulugurtha, 2011; Hurwitz et al., 2013; Huth et al., 2015). These studies used a small sample size and have not investigated the impact of using a cellphone while driving on operation and capacity of the signalized intersection with one green time operating at one approach leg of four approach legs of the signalized intersections with a 240 second cycle length, and did not include similar environmental and prevailing conditions in other countries. This study investigates the impact of cellphone usage on signalized intersection capacity and LOS in Saudi Arabia, where signalized intersections are operating one green time at one leg approach during effective green, and cycles are up to 240 seconds. This major difference in effective green operation and cycle length could lead to a higher significant statistical impact on signalized intersection capacity, delay, and LOS. The study assists transportation and traffic officials in optimizing signal operation to mitigate the impact and provide solutions. Also, the study provides a foundation to adjust signal capacity and LOS with a reduction factor associated with many cellphone users during a different time of day.

\section{Literature review}

Cell phone usage is one of the visual, cognitive, and manual distractions to driver response and reaction time to signal changes that are highly anticipated to increase Start-up Lost Time (SLT), and Average Saturation Headway (ASH) causing a reduction in signalized intersection capacity and LOS. The American Highway Capacity Manual (HCM), (Transportation Research Board, 2010), defined SLT as the additional time over ASH required by the first five drivers including response and reaction time plus vehicle re-acceleration time after the signal changes to green (Transportation Research Board, 2010). The manual also defines ASH as the average time between successive vehicles on a single lane to enter and exit the intersection after the fourth or fifth vehicle in the queue during the green time, when green time is available for an hour. It is anticipated that the time used by drivers on a cellphone while driving increases their reaction time to signal change to the green from the first to the rest of the vehicles in the queue at the signalized intersection. This will cause a reduction in signalized intersection capacity and deteriorate LOS caused by the increased reaction time of motorists, which will increase SLT and ASH. Signalized intersection capacity is the maximum number of vehicles per lane that enter and exit the intersection during green for an hour under normal and regular environmental and prevailing conditions, and is measured as ASH (Transportation Research Board, 2010). LOS defined by six letters ranging from A to F represent different categories of signalized intersection quality of operation measured by the total average delay per vehcile at signalized intersections, which is measured as SLT (Transportation Research Board, 2010).

Globally, most studies on the impact of using cell phone while driving focused on classification and characteristics of motorists that use cell phones (Amith et al., 2019; Hayashi et al., 2015; Pouyakian et al., 2013; Strayer et al., 2006; Yannis et al., 2010), assessment of perception reaction time in congestion (Stavrinos et al., 2013; Xiao and Shi, 2016; Xiong et al., 2015), factors effecting perception reaction time (National Safety Council, 2012; Xiao and Shi, 2016; Zhang and Prevedouros, 2011), comparsion of perception reaction time between texting and calling (Libby et al., 2013; Muhrer and Vollrath, 2011), flow rate and velocity at uninterrupted flow facilities like highways and freeways (Xiao and Shi, 2015), impacts on other drivers (Saifuzzaman et al., 2015; Samareh et al., 2015), policies and strategies to mitigate cell phone use (Long et al., 2013; Oviedo-Trespalacios et al., 2016). For example, in Hawaii, Zhang and Prevedouros (2011) used a driving simulator 
to collect data about perception reaction time of multiple motorists when using cell phones, and another group of motorists that drive under the influence of alcohol at $0.08 \%$ weight/volume. The study has found that cellphone use while driving had a slower reaction time than drunk driving by about 0.5 seconds. In the USA, a study investigated why driving while using hands-free cell phones is a risky behavior (National Safety Council, 2012). The study found that $9 \%$ of all participants were using their cellphone while driving, which increased driving perception reaction time by about 1.25 seconds. In Alabama, USA, Stavrinos et al. (2013) investigated the impact of distracted driving on traffic congestion using a sample of 75 motorists. The study found that using a cellphone while driving had a significant negative impact on traffic flow and speed where drivers significantly ( $p=0.02$ ) had lower lane changing frequency behavior by about one lane change. In the USA, Libby et al. (2013) investigated the difference of impact between texting and calling while driving on simulated driving performance. The study found that drivers in texting conditions had a significantly greater reaction time when lane changing was required compared to drivers in calling conditions. A study in Germany used 28 participants to investigate the effect of visual and cognitive distraction on driver's anticipation in a simulated car following behavior (Muhrer and Vollrath, 2011). The study found that visual distraction had a significantly higher reaction time to rear-end collisions by about 0.5 seconds than cognitive distractions. These reviewed studies emphasized the importance of investigating the impact of using a cellphone while driving. However, none of these studies have included the impact of using a cellphone on ASH at certain specific conditions. These studies have also focused on the impact of using a cellphone on the motorist's reaction time and neglected the impact of slower reaction time on the re-acceleration of vehicles. Investigating the impact of motorist's perception reaction time with vehicle re-acceleration time is significant where it is anticipated to be reflected on signalized intersection capacity.

However, a few studies have focused on the implications of cell phone usage on signalized intersections capacity and LOS (Brumfield and Pulugurtha, 2011; Hurwitz et al., 2013; Huth et al., 2015). For instant, in Oregon, Kansas, and Utah, in the USA, a study used the methodology in HCM (Transportation Research Board, 2010), to collect field data from 11 approaches at six signalized intersections with a sample of 3726 observations (Hurwitz et al., 2013). The study found that distracted drivers significantly increased SLT by about 1.06 seconds. In Charlotte, USA, Brumfield and Pulugurtha (2011) collected data about SLT and ASH at four signalized intersections with a sample of 3741 observations of cell phone users while driving using HCM (Transportation Research Board, 2010). The authors found that texting significantly increased SLT and $\mathrm{ASH}$ by about $1 \%$ and $2 \%$ at all locations. In Leon, France, a study collected field data at one site with a sample of 124 observations by direct traffic observation techniques and analyzed the data using Chi-square tests to compare the impact of cognitive distraction to visual manual distractions (Huth et al., 2015). The study found that total signalized intersections delay as a component of SLT has significantly increased due to cellphone use by about 0.92 seconds. These studies have found that using a cellphone while driving has increased SLT and ASH at signalized intersections by about one second on average.

However, these studies by Huth et al. (2015), Hurwitz et al. (2013), and Brumfield and Pulugurtha (2011) have some methodological limitations in terms of sample size, and the vehicle positions in the queue at intersections. First, all three studies have been conducted at one to eight locations, even though it is preferred to use several locations for better generalization of study results. Second, the studies did not distinguish the impact of cellphone use between the first to the fourth vehicle in the queue, and from the fourth to the rest of vehicles in the queue. According to the USA HCM (Transportation Research Board, 2010), it is preferred to extract SLT data from the first to the fourth vehicle in the queue and $\mathrm{ASH}$ from the fourth vehicle to the rest of the queue. Another knowledge gap in these studies is that they have investigated the impact of some specific environmental and prevailing traffic conditions that are different from other settings. For example, the studies have collected data on SLT and $\mathrm{ASH}$ at locations with a 180 second cycle length and two green time operations on two interfacing approaches. As such, it is interesting to investigate the impact of distracted driving on SLT and ASH at signalized intersections with 240 second cycles and one green time signal operation in one direction. Also, some environmental and prevailing conditions including weather conditions, land use pattern, and the number of buses, bicycles, and pedestrians on streets are different in other places. To fill this knowledge gap, the present study investigates the impact of cellphone using while driving at 24 signalized intersections with one green time operation at one direction, and 240 second cycle length on SLT and ASH, in the case of 
the first to the fourth vehicles in the queue and the fourth to the rest of the vehicles in the queue. The next section describes the methodology utilized in the study.

\section{Methodology}

\subsection{Study area}

This study was conducted in the Dammam Metropolitan Area (DMA), the capital of The Eastern Province of The Kingdom of Saudi Arabia (KSA). DMA contains three major cities of Dammam, Khobar, and Dhahran, with a total population of 1.66 million people, which has been increasing at a rate of $2.8 \%$ annually (AlQahtany and Abubakar, 2020). The metropolis, covering an area of 204896.6 square meters, is the third-largest metropolis in KSA (UN-Habitat and MOMRA, 2019a; 2019b). It is located 236 miles away from Riyadh, the capital city of KSA along the Arabian Gulf (Mu'azu et al., 2020). The first oil field in the country was discovered in 1938 in DMA, which serves as the oil capital of the country and has one of the major seaports in KSA importing and exporting oil and goods. The elevation of DMA is about 30 meters above the sea level, which does not vary among the three cities. Fig. 1 shows the location of the three cities where field data have been collected in DMA.

The roadway network length in DMA covered 312.5 miles in 2007 , where $12.13 \%$ were freeways, $72.96 \%$ were arterials, and $14.91 \%$ were major roadways (UN-Habitat and MOMRA, 2019a; 2019b). The roadway network has two directions on each road and a minimum of two lanes in each direction. The arterial roads are connecting with major collector roads in DMA through 108 signalized intersections. Trips are generated and attracted from and to the major activity centers in DMA, including two industrial cities, two CBDs, two major governmental

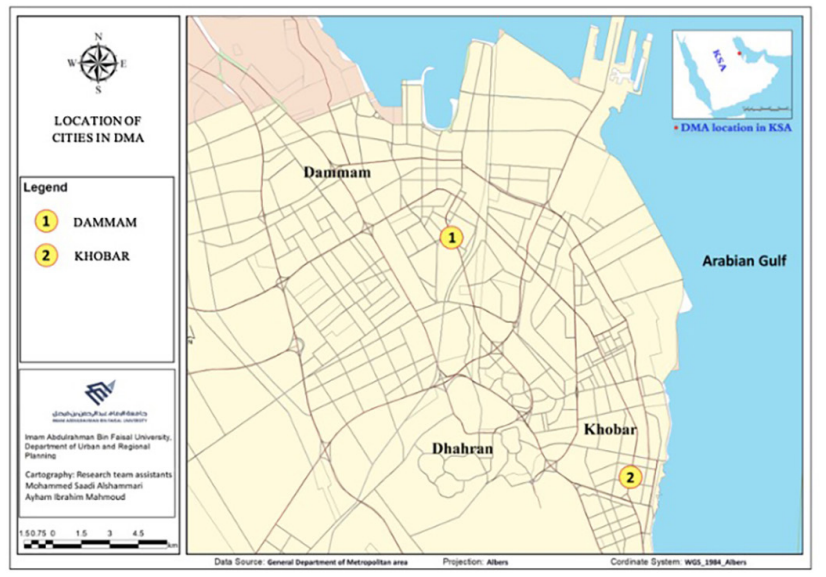

Fig. 1 Location of data collection at major cities in DMA universities, oil production and servicing companies, shopping malls, airports, seaports, and residential areas. All these trips pass through these signalized intersections where motorists are observed using their cellphones while waiting for green time. Thus, it is significant to investigate the impact of cellphone usage at signalized intersections on capacity and LOS.

\subsection{Methods}

To determine whether cellphone use at signalized intersections can increase SLT and ASH in DMA, data were collected from mid-through lanes at 24 signalized intersections by two observers for 7-10 signal cycles at each intersection during one evening hour (5-6 PM) from September to October 2019. Evening hours were selected because they are observed to be rush hours when people are returning from work and the percentage of phone use is usually high. The locations have been chosen based on the presence of adequate queue length of 10 and more vehicles in the queue and they have the following similar characteristics:

- locations with 10 and more vehicles in the queue during red light at the signalized intersection

- no exclusive turn bays or lanes

- headway has been collected during unsaturated conditions but in evening peak hours

- lane width is between 3.4 to 3.6 meters (11 to 13 feet)

- no grade

- no Parking at the signalized intersection at all cycles during data collection

- no buses within 250 feet at the signalized intersections

- no bicycles

- no countdown signals.

The data were collected following the procedures stipulated in the USA HCM (Transportation Research Board, 2010) shown in Fig. 2 (Koonce et al., 2008), illustrating the procedure for extracting SLT and ASH values at signalized intersections. At each intersection, the first observer recorded the type of driver distractions: calling or/and texting; or no distraction and the vehicle position in the queue on a paper. The second observer registered vehicles discharge time when rear tires crossed the stop line to enter the intersection during the green time using mobile stopwatch. The data for driver distraction were classified into three categories based on vehicle positions in the queue. The first category is from the first to the fourth vehicle, the second category is from the fourth to the $10^{\text {th }}$ vehicle, 


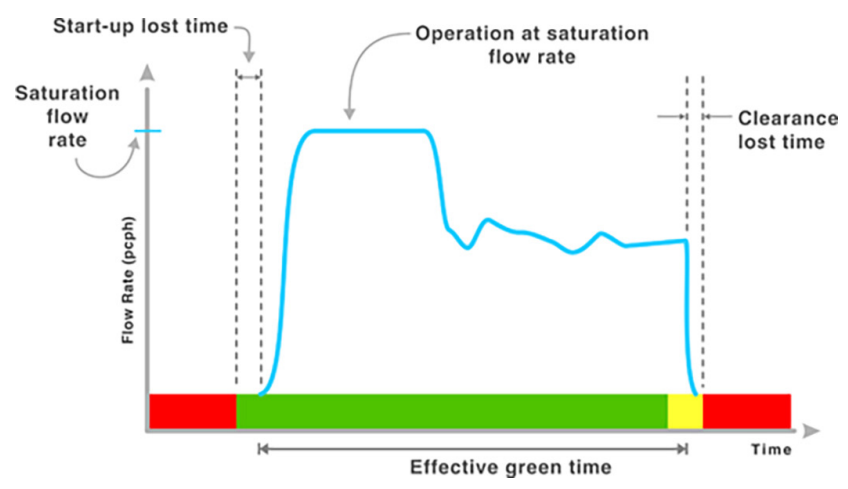

Fig. 2 The location of Start-up Lost Time as a major component of signalized intersection delay, (source: Koonce et al., 2008)

and the third category is from the first to the $10^{\text {th }}$ vehicle (Transportation Research Board, 2010). The third category indicates that more than one driver is distracted in both the first and the second vehicle categories. The data of SLT and ASH for each cycle have been extracted from the data of vehicle discharge time data in useful cycles.

For data analysis, descriptive statistics have been conducted to test data distribution normality and z-test have been used to compare SLT and ASH of cycles with driver distraction to cycles without driver distraction based on vehicle positions. To test data normality distribution, SLT and ASH data have been sorted from the smallest to the largest value. The probability distribution function of SLT has been calculated in adjacent to each value and the probability distribution curve has been generated to test the normal distribution applicability of SLT and ASH. A comparison z-test has been conducted to explore whether statistically significant differences exist between SLT at cycles without cell phone usage and cycles with cell phone usage. All vehicle positions of cell phone usage have been included individually in the test for cycles with cell phone usage according to the previous classification. As mentioned earlier in this study, cycles with cell phone usage have been classified according to vehicle position to:

1. Cycles with cell phone usage from the $1^{\text {st }}$ vehicle in the queue to the $4^{\text {th }}$ vehicle in the queue.

2. Cycles with cell phone usage from the $4^{\text {th }}$ vehicle in the queue to the $10^{\text {th }}$ vehicle in the queue.

3. Cycles with cell phone usage at both locations from the $1^{\text {st }}$ to the $4^{\text {th }}$ and from the $4^{\text {th }}$ to the $10^{\text {th }}$ vehicle.

The primary hypothesis is that cycles with driver distraction (texting and calling) have higher SLT than cycles without driver distraction (no cellphone). The secondary hypothesis is that cycles with driver distraction (texting and calling) have higher ASH than cycles without driver distraction (no cellphone). Equations (1) and (2) illustrate the two hypotheses:

$$
\begin{aligned}
& \mathrm{SLT}_{0}<\mathrm{SLT}_{1}, \\
& \mathrm{ASH}_{0}<\mathrm{ASH}_{1},
\end{aligned}
$$

where:

- $\mathrm{SLT}_{0}=$ Start-up Lost Time without driver distraction,

- $\mathrm{SLT}_{1}=$ Start-up Lost Time with driver distraction,

- $\mathrm{ASH}_{0}=$ Average Saturation Headway without driver distraction,

- $\mathrm{ASH}_{1}=$ Average Saturation Headway with driver distraction.

\section{Study findings}

This section presents the findings of the impact of cellphone usage at 24 signalized intersections on SLT and ASH in DMA. Data were collected during 202 cycles and registrations of 2407 driver distractions and vehicle discharge time data have been entered in 24 Excel spreadsheets for each signalized intersection. The driver distractions of texting/calling, or no distractions are entered against the vehicle discharge time. The data have been reduced to useful cycles based on the presence of 10 or more vehicles in the queue on the mid-through lane at the location. Accordingly, only data from 189 cycles were found useful because 31 cycles were without distractions and were classified as "no cellphone". Table 1 shows the number of useful cycles, average SLT, and ASH for each cycle with cellphones and without cellphones at all locations based on vehicle positions. The SLT has increased by $0.66 \mathrm{sec}-$ onds, 0.05 seconds, and 0.74 seconds when a motorist used their cellphone within at least one of the first four vehicles in the queue, in at least one of the fourth to the 10th vehicles in the queue, and at both vehicle positions, respectively. The impact of a cellphone on SLT increased as the vehicle position of cellphone user got closer to the intersection stop line. The ASH has increased by 0.07 seconds, 0.09 seconds, and 0.11 seconds when a motorist used his cellphone within at least one of the first four vehicles in the queue, in at least one of the fourth to the 10th vehicles in the queue, and at both vehicle positions respectively. This study found an average increase of 0.7 seconds in SLT at the locations and cycles where the drivers have been distracted both in the first to fourth vehicles and in the fourth to $10^{\text {th }}$ vehicles in the queue. The study also found that there is an average trivial increase of 0.09 seconds on ASH when there is a cellphone user at all vehicle positions. 
Table 1 Data characteristics of useful cycles based on vehicle position

\begin{tabular}{lcccc}
\hline $\begin{array}{l}\text { Variable } \\
\text { Cycles }\end{array}$ & $\begin{array}{c}\text { Cycles without driver } \\
\text { distraction }\end{array}$ & $\begin{array}{c}\text { Cycles with driver } \\
\text { distraction at the } 1^{\text {st }}-4^{\text {th }} \\
\text { vehicle in the queue }\end{array}$ & $\begin{array}{c}\text { Cycles with driver } \\
\text { distraction at } 4^{\text {th }}-10^{\text {th }} \\
\text { vehicle in the queue }\end{array}$ & $\begin{array}{c}\text { Cycles with more than one driver } \\
\text { distracted at both positions, the } \\
1^{\text {st }}-10^{\text {th }} \text { vehicle in the queue* }\end{array}$ \\
\hline $\begin{array}{l}\text { Number of useful cycles } \\
\text { SLT } \\
\text { (seconds) }\end{array}$ & 31 & 48 & 38 & 72 \\
$\begin{array}{l}\text { ASH } \\
\text { (Seconds) }\end{array}$ & 2.38 & 3.04 & 2.43 & 3.12 \\
\hline
\end{tabular}

* The category of both indicates that there is more than one cell phone user at both positions of a vehicle in the queue, some are in the $1^{\text {st }-4^{\text {th }}}$ vehicle in the queue, and others are in the $4^{\text {th }}-10^{\text {th }}$ vehicle in the queue.

In the next section, further analysis was conducted to test whether the data on SLT and ASH is normally distributed. After that, a comparison z-test has been conducted to identify if there is any significant change in SLT and ASH. Although data with a sample greater than 30 can be assumed to be normally distributed, in this study, a test of normal distribution has been conducted nonetheless (Thompson, 2012).

\subsection{Findings from the normal distribution test}

Figs. 3 and 4 show the bell-shaped probability distribution function of SLT for cycles with cell phone usage and without cell phone usage. It was found that the probability distribution function of SLT and ASH are normally distributed at all cycles classifications. According to Thompson (2012), it can be assumed that the SLT and the $\mathrm{ASH}$ are normally distributed because the sample size is more than 30. Fig. 3 shows that the mean of SLT for signal cycles without a cellphone is 2.38 seconds. Fig. 4 shows the mean for signal cycles with a cellphone is 3.04. The usage of cellphones at the 24 signalized intersections caused an average increase of 0.66 seconds. However, a statistically significant impact of a cellphone on SLT and ASH has to be tested by conducting a z-test in the next section.

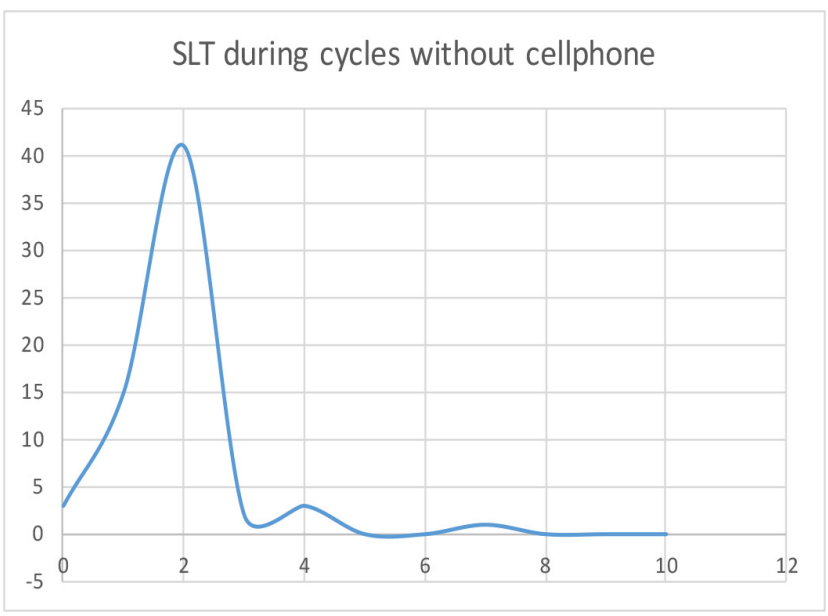

Fig. 3 SLT data distribution at cycles without cellphone usage

\subsection{Findings from the $\mathrm{z}$-test}

This study finds that there is a significant change in SLT between cycles without a cellphone to cycles with a cellphone. Using cellphones at the 24 signalized intersections significantly increased SLT by an average of 0.7 seconds. However, there was no significant change in ASH between cycles without cellphones and cycles with a cellphone.

Table 2 shows the results of the comparison analysis of SLT and ASH using z-test. The probability value of the one-tail z-test of SLT is 0.01, thus the increase in SLT of 0.66 seconds is statistically significant. While, the probability value of the one-tail z-test of ASH is 0.31 , thus the increase in ASH of 0.07 is not statistically significant. According to HCM (Transportation Research Board, 2010), the row data values of SLT have been extracted from the passing time of the first to the fourth vehicles. While the row data ASH have been extracted from the fourth to the tenth vehicles in the queue. This suggests that the impact of a cellphone is located within the first few vehicles in the queue at the intersections. The time dedicated to using cellphones by motorists in the first few vehicles in the queue significantly reduced their reaction time to signal change to green.

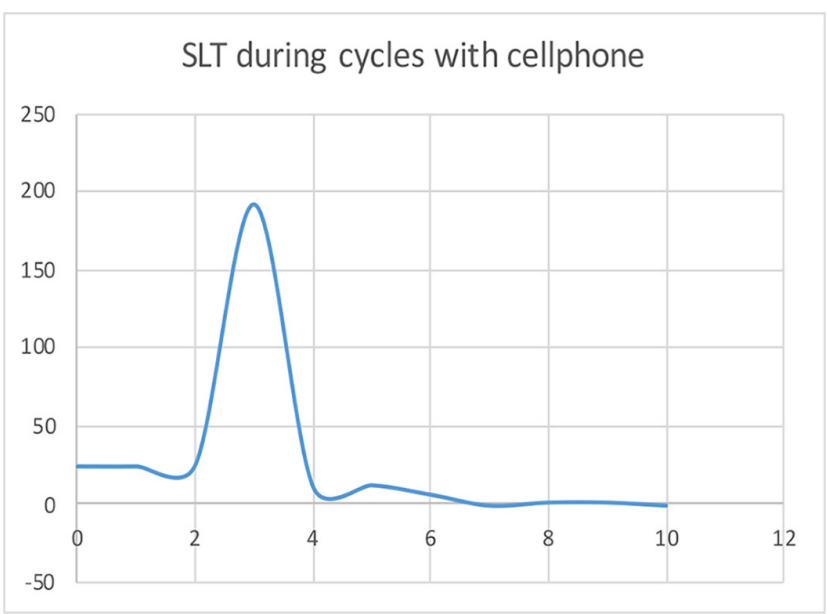

Fig. 4 SLT data distribution at cycles with cellphone usage 
Table 2 z-test of SLT for cycles without cellphone usage and cycles with cellphone usage at $1^{\text {st }} 4^{\text {th }}$ vehicle

\begin{tabular}{lcccc}
\hline & $\mathrm{SLT}_{0}$ & $\mathrm{SLT}_{c p}$ & $\mathrm{ASH}_{0}$ & $\mathrm{ASH}_{c p}$ \\
\hline Mean & 2.38 & 3.04 & 2.16 & 2.23 \\
Known Variance & 1.47 & 1.96 & 0.37 & 0.42 \\
Observations & 31 & 48 & 31 & 48 \\
Hypothesized Mean & 0 & & 0 & \\
Difference & & & -0.4911 & \\
$\mathrm{z}$ & -2.3383 & & 0.3117 & \\
$\mathrm{P}(\mathrm{Z}<=\mathrm{z})$ one-tail & 0.0097 & & 1.6449 & \\
z Critical one-tail & 1.6449 & & 0.6233 & \\
$\mathrm{P}(\mathrm{Z}<=$ z) two-tail & 0.0194 & & 1.96 & \\
z Critical two-tail & 1.96 & & & \\
\hline
\end{tabular}

Table 3 shows the results of the z-test in SLT and ASH for signal cycles without cellphone usage and cycles with cellphone user in at least one of the fourth to the tenth vehicles in the queue. The probability values of one-tail z-test for both SLT and ASH are more than 0.05, thus the increase in SLT and ASH in the case of at least one cellphone user at this position is not statistically significant. This result emphasizes on the location of the impact of cellphone usage within the first few vehicles in the queue at the 24 signalized intersections. Cellphone usage by motorists in subsequent vehicles passing the intersection stop-line does not significantly influence the value of SLT or ASH.

Table 4 shows the comparison z-test of SLT and ASH for cycles without cellphone usage and cycles with cellphone users in at least one of the first to fourth vehicles in the queue, and cellphone user in at least one of the $4^{\text {th }}$ to $10^{\text {th }}$ vehicles in the queue at the intersections. The probability value of the one-tail z-test of SLT is 0.004 , thus the increase in SLT of 0.74 seconds is statistically significant. Whereas, the probability value of the one-tail z-test of ASH is 0.21, thus the increase in ASH of 0.11 is not

Table 3 The z-test of SLT for cycles without cellphone usage and cycles with cell phone usage at $4^{\text {th }}-10^{\text {th }}$ vehicle

\begin{tabular}{lcccc}
\hline & $\mathrm{SLT}_{0}$ & $\mathrm{SLT}_{c p}$ & $\mathrm{ASH}_{0}$ & $\mathrm{ASH}_{c p}$ \\
\hline Mean & 2.38 & 2.43 & 2.16 & 2.25 \\
Known Variance & 1.47 & 1.87 & 0.37 & 0.44 \\
Observations & 31 & 38 & 31 & 38 \\
Hypothesized Mean & 0 & & 0 & \\
Difference & & & -0.5663 & \\
$\mathrm{z}$ & -0.1575 & & 0.2856 & \\
$\mathrm{P}(\mathrm{Z}<=\mathrm{z})$ one-tail & 0.4374 & & 1.6449 & \\
$\mathrm{z}$ Critical one-tail & 1.6449 & & 0.5712 & \\
$\mathrm{P}(\mathrm{Z}<=\mathrm{z})$ two-tail & 0.8749 & & 1.96 & \\
$\mathrm{z}$ Critical two-tail & 1.96 & & & \\
\hline
\end{tabular}

Table 4 The z-test of SLT for cycles without cellphone usage and cycles with cellphone usage at $1^{\text {st }}-10^{\text {th }}$ vehicle

\begin{tabular}{lcccc}
\hline & $\mathrm{SLT}_{0}$ & $\mathrm{SLT}_{c p}$ & $\mathrm{ASH}_{0}$ & $\mathrm{ASH}_{c p}$ \\
\hline Mean & 2.38 & 3.12 & 2.16 & 2.27 \\
Known Variance & 1.47 & 2.07 & 0.37 & 0.51 \\
Observations & 31 & 72 & 31 & 72 \\
Hypothesized Mean & 0 & & 0 & \\
Difference & & & -0.8107 & \\
z & -2.6672 & & 0.2088 & \\
P(Z<=z) one-tail & 0.0038 & & 1.6449 & \\
z Critical one-tail & 1.6449 & & 0.4175 & \\
P(Z<=z) two-tail & 0.0076 & & 1.96 & \\
z Critical two-tail & 1.96 & & & \\
\hline
\end{tabular}

statistically significant. Thus, Tables 2 and 4 show that the impact of a cellphone usage is on SLT only, and only whenever there is a cellphone use within at least one of the first to the fourth vehicles in the queue. This result emphasizes the location of the impact of cellphone usage within the first few vehicles in the queue. However, the impact of a cellphone usage on SLT has increased when there was more than one cellphone user. Using cellphones by the motorists of the first few vehicles in the queue reduces motorists' reaction response time to signal change to green. This result also suggests that using a cellphone does not decrease lane capacity.

For further data investigation and analysis, cycles with cellphone usage that significantly and statistically influence the SLT have been merged in Excel Spreadsheet. The sheet included cycles without cellphone usage and cycles with cellphone usage at $1^{\text {st }}$ to $4^{\text {th }}$ vehicles in the queue and cycles with cellphone usage at both vehicle positions ( $1^{\text {st }}$ to $4^{\text {th }}$, and $4^{\text {th }}$ to $10^{\text {th }}$ vehicle in the queue). Table 5 shows that there is a statistically significant average increase in SLT equal to 0.7 seconds due to using a cellphone by a motorist in at least one of the vehicles within the $1^{\text {st }}$ to $10^{\text {th }}$ vehicles in the queue.

Table 6 shows that the probability value of the z-test at one-tail is less than 0.05 . Tables 5 and 6 show that using a cellphone at a signalized intersection significantly increases SLT by 0.7 seconds.

Table 5 Data summary of merged classification of cycles with cell phone usage

\begin{tabular}{lcccc}
\hline & $\begin{array}{c}\text { Cycles without } \\
\text { cellphone usage }\end{array}$ & SLT $_{0}$ & $\begin{array}{c}\text { Cycles with } \\
\text { cellphone usage }\end{array}$ & SLT $_{c p}$ \\
\hline $\begin{array}{l}\text { Number of } \\
\text { Cycles }\end{array}$ & 31 & 31 & 120 & 120 \\
Average & 31 & 2.38 & 120 & 3.08 \\
\hline
\end{tabular}


Table 6 A comparison z-test of cycles without cellphone usage and cycles with cellphone usage at $1^{\text {st }}-10^{\text {th }}$ vehicle

\begin{tabular}{lll}
\hline & SLT $_{0}$ & SLT $_{c p}$ \\
\hline Mean & 2.38 & 3.08 \\
Known Variance & 1.47 & 2 \\
Observations & 31 & 120 \\
Hypothesized Mean Difference & 0 & \\
$\mathrm{z}$ & -2.2871 & \\
$\mathrm{P}(\mathrm{Z}<=\mathrm{z})$ one-tail & 0.0111 & \\
$\mathrm{z}$ Critical one-tail & 1.6449 & \\
$\mathrm{P}(\mathrm{Z}<=\mathrm{z})$ two-tail & 0.0222 & \\
$\mathrm{z}$ Critical two-tail & 1.96 & \\
\hline
\end{tabular}

\section{Discussion}

This study assessed the effect of using a cellphone at 24 signalized intersections based on vehicle position in the queue. The study found that using cellphone significantly increases SLT by 0.7 seconds, which can cause a reduction of 0.7 seconds in effective green time. The effective green time is the time in seconds dedicated to vehicle progression under normal environmental and prevailing conditions during actual signal green time. Accordingly, the reduction in effective green time by 0.7 seconds can lead to an increase in total delay per vehicle, which can reduce the progression of 13 vehicles per phase. This value can result in a reduction of one useless phase of effective green time at signalized intersections per hour causing a deterioration in signalized intersection capacity and LOS by increasing delay (Hurwitz et al., 2013), and reduce driving performance (Thapa et al., 2015). This deterioration in signalized intersection capacity and LOS is associated with a reduction in vehicle mobility, accessibility, and network productivity (Brumfield and Pulugurtha, 2011; Huth et al., 2015). Increased delay in mobility can reduce accessibility to major activity centers in DMA and other cities where cellphones are used at intersections. The reduction in accessibility could eventually cause a reduction in individual productivity per hour. Using a cellphone while driving in Saudi Arabia with the dominance of private vehicles, which is 219 cars per 1000 inhabitants, can increase overall delay and traffic congestion with its attendant impact of contributing to climate change (Abubakar and Dano, 2020).

Many studies investigated the impact of cellphone usage on traffic safety at different parts of transportation networks. In the literature, similar results on the impact of cellphone usage on SLT have been found globally. Hurwitz et al. (2013) found an increase in SLT by
1.0 second and Huth et al. (2015) reported an increase of 0.92 seconds. The difference in the values is related to the difference in driving behaviors, patterns, and demand from country to country. For example, a study by Brumfield and Pulugurtha (2011) has found an increase from $1 \%$ to $2 \%$ on SLT by cellphone use at signalized intersections. It is recommended for transportation and traffic engineering officials to adopt and deploy countdown signal timer to minimize the impact of using cell phone (Liu et al., 2012; Long et al., 2013). Many studies have found that countdown timer at signalized intersection enhances vehicle progression and increases queue discharge flow. In China, a study has been conducted to identify the effects of countdown timer on queue discharge flow characteristics through movement at signalized intersections (Liu et al., 2012). The study conducted a t-test on collected data of SLT and ASH at signalized intersections for 24 hours when the countdown signal was operating and when it was off and found that SLT decreased from 1.92 seconds to 1.0 seconds per cycle (Liu et al., 2012). Another study in China, used field data to investigate the impact of countdown timers on ASH and found a reduction of 0.82 seconds on ASH (Long et al., 2013). The study model predicts a reduction of 0.72 seconds on ASH of the first vehicle in the queue at the signalized intersections. These studies have shown that using signal countdown timers has positive implications on the capacity and delay of the signalized intersection.

\section{Conclusion}

The present study is one of the few that investigated the impact of cellphone usage on traffic capacity presented by SLT and ASH. This study has assessed the effect of using a cellphone at 24 signalized intersections based on vehicle position in the queue in DMA of KSA and found that using a cellphone significantly increases SLT by $0.7 \mathrm{sec}-$ onds. Even though the increase in SLT and the reduction in effective green is trivial, the impact is statistically significant and associated with an increase in signal uniform delay and reduce LOS. Accordingly, it has been estimated that the reduction of 0.7 seconds on the effective green is associated with a reduction of 13 vehicles during each phase, which is $6 \%$ of the total number of phases during each hour. Thus, signal capacity per hour can be reduced due to the reduction of around $6 \%$ vehicle/hour. This study concludes that the impact of using a cellphone at the signalized intersection on SLT increases as the vehicle gets closer to the intersection stop line. Future studies should 
be conducted using more data, either field or simulated, to calibrate reduction factors associated with cellphone usage for a whole day based on vehicle position.

\section{Acknowledgements}

The author would like to thank dr. Abubakar for his support and comments in typing, editing, and reviewing the manuscript.

\section{References}

Abubakar, I. R., Dano, U. L. (2020) "Sustainable urban planning strategies for mitigating climate change in Saudi Arabia", Environment, Development, and Sustainability, 22(6), pp. 5129-5152. https://doi.org/10.1007/s10668-019-00417-1

Alm, H., Nilsson, L. (1995) "The effects of a mobile telephone task on driver behavior in a car following situation", Accident Analysis \& Prevention, 27(5), pp. 707-715. https://doi.org/10.1016/0001-4575(95)00026-V

AlQahtany, A. M., Abubakar, I. R. (2020) "Public perception and attitudes to disaster risks in a coastal metropolis of Saudi Arabia", International Journal of Disaster Risk Reduction, 44, Article number: 101422 . https://doi.org/10.1016/j.ijdrr.2019.101422

Brumfield, R. M., Pulugurtha, S. S. (2011) "Effect of Driver Cell Phone Use on Queue Discharge Patterns at Signalized Intersections", Transportation Research Record: Journal of the Transportation Research Board, 2257(1), pp. 71-79. https://doi.org/10.3141/2257-08

Hayashi, Y., Russo, C. T., Wirth, O. (2015) "Texting while driving as an impulsive choice: A behavioral economic analysis", Accident Analysis \& Prevention, 83, pp. 182-189. https://doi.org/10.1016/j.aap.2015.07.025

Hurwitz, D. S., Heaslip, K. P., Schrock, S. D., Swake, J., Marnell, P., Tuss, H., Fitzsimmons, E. (2013) "Implications of Distracted Driving on Start-Up Lost Time for Dual Left-Turn Lanes", Journal of Transportation Engineering, 139(9), pp. 923-930. https://doi.org/10.1061/(ASCE)TE.1943-5436.0000569

Huth, V., Sanchez, Y., Brusque, C. (2015) "Drivers' phone use at red traffic lights: A roadside observation study comparing calls and visual-manual interactions", Accident Analysis \& Prevention, 74, pp. $42-48$.

https://doi.org/10.1016/j.aap.2014.10.008

Khandakar, A., Chowdhury, M. E. H., Ahmed, R., Dhib, A., Mohammed, M., Al-Emady, N. A. M. A., Michelson, D. (2019) "Portable System for Monitoring and Controlling Driver Behavior and the Use of Mobile Phone While Driving", Sensors, 19(7), Article number: 1563.

https://doi.org/10.3390/s19071563

Koonce, P., Rodegerdts, L., Lee, K., Quayle, S., Beaird, S., Braud, C., ..., Urbanik, T. (2008) "Traffic Signal Timing Manual", U.S. Department of Transportation, Federal Highway Administration, McLean, VA, USA, Rep. FHWA-HOP-08-024.
The author confirm contribution to the paper as follows: study conception and design: Nawaf Alshabibi; data collection: Nawaf Alshabibi; data analysis and interpretation of results: Nawaf Alshabibi; draft manuscript preparation: Nawaf Alshabibi; reviewing the results and final version of the manuscript: Nawaf Alshabibi.

The corresponding author states that there is no conflict of interest.

Libby, D., Chaparro, A., He, J. (2013) "Distracted While Driving: A Comparison of the Effects of Texting and Talking on a Cell Phone", In: Proceedings of the Human Factors and Ergonomics Society Annual Meeting, (57)1, pp. 1874-1878.

https://doi.org/10.1177/1541931213571418

Liu, P., Yu, H., Wang, W., Ma, J., Wang, S. (2012) "Evaluating the Effects of Signal Countdown Timers on Queue Discharge Characteristics at Signalized Intersections in China", Transportation Research Record: Journal of the Transportation Research Board, 2286(1), pp. 39-48.

https://doi.org/10.3141/2286-05

Long, K., Liu, Y., Han, L. D. (2013) "Impact of countdown timer on driving maneuvers after the yellow onset at signalized intersections: An empirical study in Changsha, China", Safety Science, 54, pp. 8-16.

https://doi.org/10.1016/j.ssci.2012.10.007

Mu'azu, N. D., Abubakar, I. R., Blaisi, N. I. (2020) "Public acceptability of treated wastewater reuse in Saudi Arabia: Implications for water management policy", Science of The Total Environment, 721, Article number: 137659.

https://doi.org/10.1016/j.scitotenv.2020.137659

Muhrer, E., Vollrath, M. (2011) "The effect of visual and cognitive distraction on driver's anticipation in a simulated car following scenario", Transportation research part F: Traffic Psychology and Behaviour, 14(6), pp. 555-566. https://doi.org/10.1016/j.trf.2011.06.003

National Highway Traffic Safety Administration (NHTSA) (2010) "Distracted Driving in 2009", U.S. Department of Transportation, Washington, USA, DOT HS 811379.

National Safety Council (2012) "Understanding the distracted brain: Why driving while using hands-free cell phones is risky behavior", [pdf] National Safety Council, Itasca, IL, USA, Available at: https:// www.nsc.org/getmedia/2ea8fe8b-d7b7-4194-8ea5-306d30a73972/ cognitive-distraction-white-paper.pdf [Accessed: 02 April 2020]

Oviedo-Trespalacios, O., King, M., Vaezipour, A., Truelove, V. (2019) "Can our phones keep us safe? A content analysis of smartphone applications to prevent mobile phone distracted driving", Transportation Research Part F: Traffic Psychology and Behaviour, 60, pp. 657-668.

https://doi.org/10.1016/j.trf.2018.11.017 
Oviedo-Trespalacios, O., Haque, M. M., King, M., Washington, S. (2016) "Understanding the impacts of mobile phone distraction on driving performance: A systematic review", Transportation Research Part C: Emerging Technologies, 72, pp. 360-380. https://doi.org/10.1016/j.trc.2016.10.006

Pouyakian, M., Mahabadi, H. A., Yazdi, S. M., Hajizadeh, E., Nahvi, A. (2013) "Impact of Headway Distance and Car Speed on Drivers' Decisions to Answer an Incoming Call", Traffic Injury Prevention, 14(7), pp. 749-755.

https://doi.org/10.1080/15389588.2012.749464

Prat, F., Gras, M. E., Planes, M., Font-Mayolas, S., Sullman, M. J. M. (2017) "Driving distractions: An insight gained from roadside interviews on their prevalence and factors associated with driver distraction", Transportation Research Part F: Traffic Psychology and Behaviour, 45, pp. 194-207.

https://doi.org/10.1016/j.trf.2016.12.001

Saifuzzaman, M., Haque, M. M., Zheng, Z., Washington, S. (2015) "Impact of mobile phone use on the car-following behavior of young drivers", Accident Analysis \& Prevention, 82, pp. 10-19. https://doi.org/10.1016/j.aap.2015.05.001

Samareh, A., Xu, J., Benneyan, J. C., Lin, Y. (2015) "Study the Headway Distance and Physiological Responses of Driver Distraction An experiment on Networked Multi-Drivers Simulator", Proceedings of the Human Factors and Ergonomics Society Annual Meeting, 59(1), pp. 1820-1823. https://doi.org/10.1177/1541931215591393

Smith, M. R., Witt, G., Zhang, H. (2010) "Method of mitigating driver distraction", Patent and Trademark Office, Washington, DC, USA, US-7835834-B2.

Stavrinos, D., Jones, J. L., Garner, A. A., Griffin, R., Franklin, C. A., Ball, D., ..., Fine, P. R. (2013) "Impact of distracted driving on safety and traffic flow", Accident Analysis \& Prevention, 61, pp. 63-70. https://doi.org/10.1016/j.aap.2013.02.003

Strayer, D. L., Drews, F. A. (2003) "Effects of Cell Phone Conversations on Younger and Older Drivers", Proceedings of the Human Factors and Ergonomics Society Annual Meeting, 47(16), pp. 1860-1864. https://doi.org/10.1177/154193120304701606

Strayer, D. L., Drews, F. A., Crouch, D. J. (2006) "A Comparison of the Cell Phone Driver and the Drunk Driver", Human Factors: The Journal of the Human Factors and Ergonomics Society, 48(2), pp. 381-391. https://doi.org/10.1518/001872006777724471

Thapa, R., Codjoe, J., Ishak, S., McCarter, K. S. (2015) "Post and During Event Effect of Cell Phone Talking and Texting on Driving Performance - A Driving Simulator Study", Traffic Injury Prevention, 16(5), pp. 461-467. https://doi.org/10.1080/15389588.2014.969803

Thompson, S. K. (2012) "Sampling", John Wiley \& Sons, Hoboken, NJ, USA.

https://doi.org/10.1002/9781118162934
Transportation Research Board (2010) "Highway Capacity Manual 2010 (HCM2010)", The National Academies of Sciences Engineering Medicine, Washington, DC, USA.

UN-Habitat, MOMRA (2019a) "CPI Profile: Dammam", [pdf] United Nations Human Settlements Programme, Nairobi, Kenya, Ministry of Municipal and Rural Affairs, Riyadh, Saudi Arabia. Available at: https://unhabitat.org/sites/default/files/2020/04/cpi profile_for_damman_2019.pdf [Accessed: 08 May 2020]

UN-Habitat, MOMRA (2019b) "Saudi Cities Report 2019", [pdf] United Nations Human Settlements Programme, Nairobi, Kenya, Ministry of Municipal and Rural Affairs, Riyadh, Saudi Arabia. Available at: https:/unhabitat.org/sites/default/files/2020/05/ saudi_city_report.english.pdf [Accessed: 08 May 2020]

Wu, J., Xu, H. (2018) "The influence of road familiarity on distracted driving activities and driving operation using naturalistic driving study data", Transportation Research Part F: Traffic Psychology and Behaviour, 52, pp. 75-85. https://doi.org/10.1016/j.trf.2017.11.018

Xiao, Y., Shi, J. (2015) "Analyzing the Influence of Mobile Phone Use of Drivers on Traffic Flow Based on an Improved Cellular Automaton Model", Discrete Dynamics in Nature and Society, 2015, Article ID: 573090. https://doi.org/10.1155/2015/573090

Xiao, Y., Shi, J. (2016) "Study on the influence of driving distraction on traffic flow considering the stochastic duration time of distraction", Modern Physics Letters B, 30(32n33), Article number: 1650380. https://doi.org/10.1142/S0217984916503802

Xiong, H., Bao, S., Sayer, J., Kato, K. (2015) "Examination of drivers' cell phone use behavior at intersections by using naturalistic driving data", Journal of Safety Research, 54, pp. 89-93. https://doi.org/10.1016/j.jsr.2015.06.012

Yannis, G., Papadimitriou, E., Karekla, X., Kontodima, E. (2010) "Mobile phone use by young drivers: effects on traffic speed and headways", Transportation Planning and Technology, 33(4), pp. 385-394. https://doi.org/10.1080/03081060.2010.494030

Yuanyuan, W., Cunbao, Z., Bin, Z., Feng, C., Hualong, Z. (2017) "The mobile phone use behavior and its effect on pedestrian safety at signalized intersections in China", In: The 4th International Conference on Transportation Information and Safety (ICTIS), Banff, AB, Canada, pp. 225-231. https://doi.org/10.1109/ICTIS.2017.8047769

Zhang, L., Prevedouros, P. D. (2011) "User perceptions of signalized intersection level of service using fuzzy logic", Transportmetrica, 7(4), pp. 279-296. https://doi.org/10.1080/18128601003667460 